us from the sun, is a compound or mixture of many colors.
The different colors of bodies are said to be due to the way they reflect the different kinds of light, by creating in the imaginary ether waves of different lengths. These waves, supposed to move simultaneously and perfectly distinct, so
that each will produce its own separate and characteristic that each will produce its own separate and characteristic
effect upon the or gans of vision. Such is the modern scientific theory as to the creation of
colors. I must confess that my understanding is not much enlightened by it as by the emission theory of Newton. The solar spectrum exhibits seven principal colors, but nity of intermediate tints. I find it bard to iugagine seve
nathe waves of different lengths, all moving with equal speed and striking the retina of the eye at the same moment; but lengths of waves-representing the infinity of intermediat tints-striking the retina in the manner described. If I to comprehend the emission than the undulatory theory. know that all things are growing older, and therefore under-
going an unceasing change, and I cannot understand how going an unceasing change, and I cannot understand how
such change can take place without the emission of something.
What is that What is that something? It seems to me that it is the
cause of all the changes perpetually taking place in nature. It is by this emission (or by this absorption) that I become acquainted with the several qualities of things and their relationship to my own organism. Something is constantly passing between all bodies, hy which they act and react
upon each other; by which they are at once separated and physiological-is produced and which is at the same time the origin of life and the cause of decay. This something appeals to our senses in many phases-as heat or cold, as
odors. as sounds, as colors, differentiated into forms sizes, as tastes, as the various impressions of touch or feeling, etc. This something, in its many forms and quali
ties, in its attractions and requlsions, and, in short, by the infinity of its phenomena, constitutes the reality of which sugrested g ravity is due not to " occult qualities supposed suggested, $g$ ravity is due not to " occult qualities supposed
to result from the specific forms of things, but as general
lawos of nature by rohich the things themselves are formed; their lawos of nature by vohich the things themselves are formed; their

not discoverea."
Nor are the impressions of distant objects communicated
through the senses of no physical account in building up through the senses of no physical account in building up or less permanently in the memory, and assist in creating brain may, in fact, be described as a storehouse of such im. pressions, in which are gathered not ouly the experience of conceivable beginning. And as is the brain, so is the body. strikes upon our senses from surrounding objects may be
siid to have in it " the promise and potency of every form and quality of life." those of he impressions received from outward objects, those of heat and light are the most active in producing
change. Heat is the moving agent in all manufacturing change. Heat is the moving agent in all manufacturing
processes having for their object the spcedy conversion or important elements in connection with all the phenomena important elements in connection with all the phenomena air is evolved the tender bud, thegreenleaf, the woody fiber, every form and description of vegetation, every variety and
tint of color, every kind of odor, and numerous other qualities by which our

And yet it is said that light and heat can create nothing or destroy nothing; that they are mere modes of motion-
the action of the "eternal and imperishable" parts of the huge machinery of the universe, which change only in their
relation to each other and not in their constitution. If this meant that heat and light can, in the alisolute sense, create or destroy nothing, no objection could reasonably be made.
We know nothing of either matter or motion beyond the impressions which they communicate to our consciousness
through the senses. The forces of nature may indeed be described as only the agents by which the Supreme Creator works out His purposes in the universe; but are we not,
therefore, all the less justifiable, when we see these wonderful creations of light and heat, in denying that they are what they appear to be, transmutations, in some degree, of constituted? That is, a transmus matter, which is only a metaphysical conception) of the several qualities by which the objects are presented to our
consciousness, and by which alone they are known to us? consciousness, and by which alone they are known to us?
While some scientists treat heat as only a mode of While some scientists treat heat as only a mode
motion, an accident or condition of matter-otbers conmotion, an accident or condition of matter-otbers con-
stantly refer to it as an entity of absolute power. Hence heat is utilized in warming the planetary bodies, and how immensely more is wasted in space. I do not dispute that the sun, like everything else in nature, is undergoing
changes, or "growing older "” but let this be remembered, that heat, such as it is known to us on the earth, may be something very different at its source; that, in fact, there is
no reason to believe that the sun is being burnt up like the coals upon our fires. On the contrary, there is much reason to believe the reverse. Only a few miles up in the air it is freezing coid; the light rays illuminate the regions above the clouds, but the heat rays are absent! Certainly no
evidence this of immutable heat (or even of heat such as it is known to us by combustion) radiating from the sun in space. If we place a sheet of glass before the fire, the heat
rays are stopped till the glass itself becomes hot; or if we place a sheet of ice in the same position, the same result ensues till the ice is melted. On the assumption that the sun is throwing off heat like a fire, the thin air of the upper
regions acts like a sheetof glass or ice, with this remarkable regions acts like a sheetof glass or ice, with this remarkable
difference, that the heat never raises the temperature of the thiference, that the heat never raises the temperature of the
air, and yet (apparently, at least) it gets through it, as known through but nosness on the earth's surface! The heat get Rumford showed that calorific rays can be passed through a vacuum without losing their temperature in the passage.
The question of the -temperature of the sun has been the subject of in vestigation by many scientists. Newton, one of and after lim all the scientists who have been occupied with calorimetry have followed vis example. All have believed themselves successful, and have formulated their results with great confidence. The following, in the chronologica order of the publication of the results, are the temperatures
(in centigrade degrees) found by eash of them: Newton,

$1,669,300^{\circ}$; Pouillet, $1,461^{\circ}$; Zölner, $102,200^{\circ}$; Secchi, dium can easily be secured by using the solution employed
$5,344,840^{\circ}$; Eriesson, 2,726,700

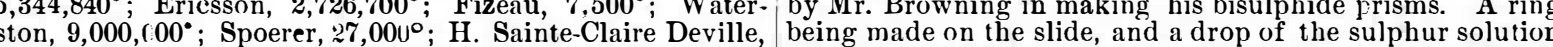

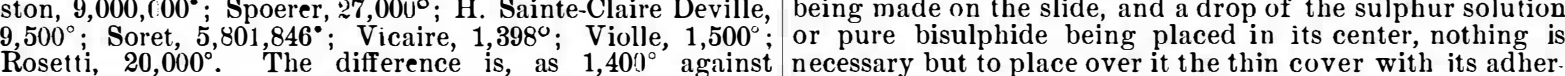
$9,1.00,000^{\circ}$, or no less than $8,998,600^{\circ} !$ There probably does ing diatoms, press it down on the still moist ring, running

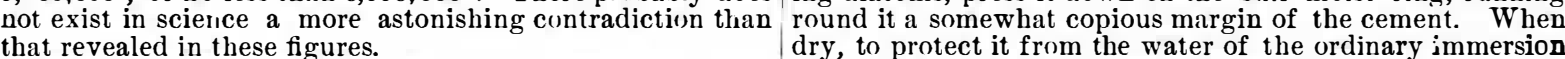
$\begin{array}{ll}\text { Another of the fallacies respecting heat upon which some } & \text { dry, to protect it from the water of the ordinary immersion } \\ \text { lenses, it is desirable to give it a coat of gold-size or shellac }\end{array}$ curious theories bave been founded as to the earth's future varnish.

destiny, is that of assuming that all but its crust is a mass
of liquid fire. In support of this intense central heat, it was at one time asserted that the temperature of deep mines
invariably increased in proportion to the depth; but doubts have, in late years, been thrown upon the statement. Still
it is confidently asserted that the interior of the earth is in a it is confidently asserted that the interior of the earth is in a
red-hot molten condition, and that it is radiating its heat
into space, ind so growing colder. One of the results of the Challenger and other explorations of deep ocean is to deter-
mine that the water toward its bottom is freezing cold. Considering that the ocean covers nearly three-fourths of the entire globe, this fact certainly does not support the theory
of central heat accompanied by radiation. The coldest of central heat accompanied by radiation. The coldest
water, it is true, usually sinks by its greater weight toward the bottom, and that, it may be said, accounts for its
coldness; but, on the theory of radiation, the water of the coldness; but, on the theory of radiation, the water of the been constantly escaping; and yet it is still of freezing cold-
bent ness! Experience would say that he heat cannot have escaped through the water without warming it, because the capacity-
of water for heat is greater than that of any other substance. We can no more imagine such a radiation, and consequent
ccumulation of heat in the ocean, without the natural result of a great rise in temperature, than we can behe usual result of boiling water. We have no reason,
herefore, to believe, as has been suggested, that the earth herefore, to believe, as has been suggested, that the earth
growing colder, or that we, in common with all living things, are destined to be frozen out of existence and the
earth itself finally swallowed up by the sun.-Journal of PHOTOPHONIC EXPERIMENTS OF PROF. A. G.
BELL AND M. SUMNER TAINTER. By A. BREGUET.

THrs paper cannot be reproduced without the accompa-
ing illustration. The question arises whether it is nsing illustration. The question arises whether it is light
or heat which is brought into play. M. Bell has placed Thefore the pencil of rays a solution of alum and then a solu-
tion of iodine. In the former case the sonorous effects were little reduced in intensity, while in the latter scarcely any DISTRIBUTION OF LIGHT IN THE SOLAR
SPECTRUM. By J. Macé and W. Nicati

IN al, cases the maximum intensity is in the yellow at a point very near to the ray $\mathrm{D}$, in conformity with the gen-
erally received opinion. The intensity decreases very rap-
idly from this point on either hand, and becones very idly from this point on either hand, and becomes very feehle minishes much more slowly with the decrease of illumination than does that of the less refrangible colors. From the extreme red to the green of the wave length $0.5 \mu$, the law of
the distribution of intensity remains absolutely the same, whatever may be the illumination. Even between eyes
equally capable of distinguishing colors there are very sen-
sible differences. MOUNTING MICROSCOPIC OBJECTS

DR. H. STOLTERForTh, M.A., in a communication to the Quekett Club recommends boiling in soap and water as a where it is available, in preference to the ordinary mode of
treatment with acids and strong alkaline solutions. He considers it far less liable to do mischief to the delicate organ
structures under treatment than the ordinary methods.

IN a paper read before the Royal Microscopical Societ Mr. J. W. Stephenson demonstrated that the visibility of
minute objects depended upon the difference between the refractive index of the medium in which they were viewed
and that of the objects themselves, and, further, that it was useless to employ objectives of the large apertures now atof utilizing the whole of large pencil; by using them on objects mounted in air their effectiveness is reduced to the lowing table of indices is given:

Wir..........

Diatomaceous silex
Sulphuric acid.

Canada balsam.

Bisulphide carbon

(n) bulphur in bisulphide carbon Sulphur. .

Solution of phosphorus in bisulphide equal $1 \cdot 00$

tomaceous silex and the several mounting media, the followg results are obtained:

Water............

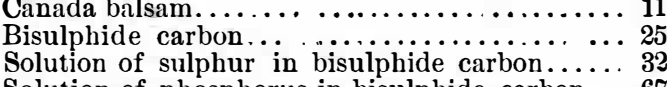

Solution of phosphorus in bisulphide carbon...6 67
The practical result of the investigation appears to be

That it is essential, if the whole aperture of an objective is to be utilized, to mount minute structures in some mediThat although the full aperture and revolving power are
ecured by mounting in balsam, it gives nevertheless nearly secured by mounting in balsam, it gives nevertheless nearly
the faintest image of all.

That a solution of phosphorus is, as far as visibility is concerned, by far the most effective, but
ing its use must render it unpopular.

The next best is a solution of sulphur in bisulphide carbon (although pure bisulphide is very good), and with
these there is no technical difficulty whatever. This

\section{NEW SUN DIAL}

By M. GRootTEN.

THE basis of this new instrument is formed by an inclined disk, $a b$, which is divided into hours and into partitiors of five minutes. This disk rests upon a foot, $h$, the lower part
of which is provided with three points. which enables the nstrument to be so placed that the disk forms with the

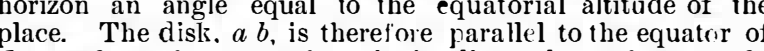
the earth or heavens when it is directed north or south. this axis a needle, $i k$, provided at its extremities with sliding rules (verniers), and upon which the plate, $c d i k$ an, is
perpendicularly fastened ; $c d$ and $e f$ are, besides, part of While the center of which is in $m$. Wh half degrees, the back part carries a bar, $p n$, $n^{1} p^{1}$, which turns around an axis at the point, $m$. At $n$ and $n^{1}$ there are
sliding rules which serve for determining the precise position of the bar. To the extremities of this bar are fastened perpendicularly two small plates, $p$ and $p^{1} ; p^{1}$ has four of $p$ which is turned toward $p^{1}$ has two lines which cross When the apparatus has to be used, it must be so placed that the sunlight shines through the four little holes, and so that the four small round images of the sun are projected
into the angles wlich are formed by the two crossing lines of the plate, $p$. In order to permit this, the bar $p p^{1}$, must
be moved either upward or diownwal $\mathrm{d}$ until its direction forms with the equatorial surface, $a b$, or with the line, $o m$ of as many degrees or minutes as the sun is above or below the equator; in other words the angle nust be that of the
solar declension of the day. Now, when the bar, $p \boldsymbol{p}^{1}$, has a direction which is equivalent to the solar declension of the
day of observation, by its aid, the exact equatorial position
of the plate, $a b$, can be easily determined. There are only

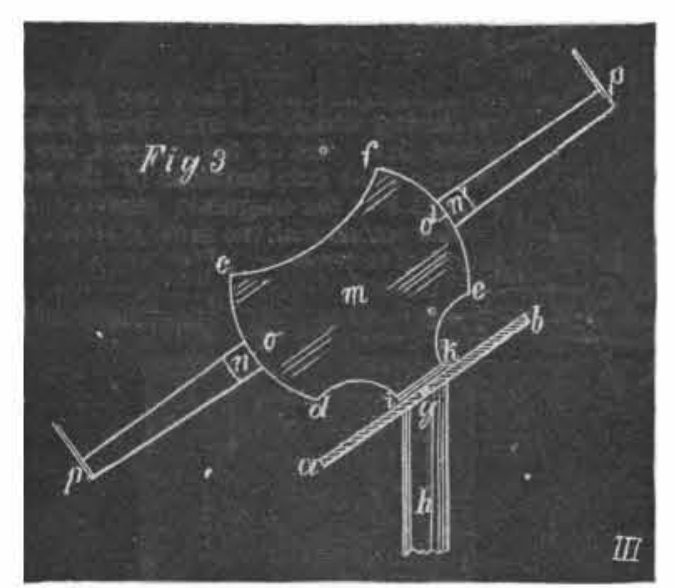

wo positions of this plate possible, by which the solar noon, the other in the afternoon. Except at the hour of noon there can be no doubt as to which of the two positions
has to be chosen, and by raking aim with the eye the pohas to be chosen, and by taking aim with the eye the po-
sition of the bar by which the images of the sun are re-
flected in the desired manner can be easily established First, without touching the bar, $i k$, with the plate, $c$ de $f$ is turned so that the shadow, $p^{1}$, falls upon $p ;$ the position of this plate has now to be fixed by screwing the foot up or down, till the solar rays pass through $p^{1}$, and strike $p$ at the
exact height, then the needle, $i k$, is turned until the luminous little circles have their position between the angles
of the cross, an observation which can be made with great precision.

At this moment the plate, $a b$, has attained the desired position, and the hours can be read of at the extiemities of the needle, $i k$. Taking the changes in the declension into consideralion, the correct position of the apparatus may be
verified at different hours, a single observation being always more or less inexact. When the correct position of the tion to the plate, $c d e$. This plate remains in its place, and the apparatus is turned from above around its axis, $g$, and the bar, $p p^{1}$, around its center, $m$, until the solar images
appear at their place. The hour can now easily be found. The sun dial can be removed from its place after the obserfound again, if the position of the three points of the foot is carefully marked. This apparatus will be of great ad
vantage for the operation of city clocks, and is sold by vantage for the operation of city clocks, and is sold by
the inventor, with the exception of its brass basis.

ANTOINE CESAR BECQUEREI.

Antorne Cesar BecQ Uerel, the distinguished French

physicist, was born at Chatillon-sur.Loing, March 7, 1788. He received his education at the Poljtechnic School, which with the army in Spain. In 1815 he retired with the rank of major, having the year pevious been named Inspector of his mineralogical and geological researches. In investigating the physical properties of amber, he was led to experiment on the discharges of electricity by means of pressure, investigations. These researches led to the refutation of the "theory of contact," by which Volta had explained the
action of his pile or battery, and to the construction of the frst electrical apparatus with a constant current. M. Becquerel's various memoirs on different bran ches of elec-
tricity, etc., have been published in the Comptes Rendus of
the Academie des Sciences and in the Annales de Physique 